\title{
Stillness (in 5 minutes)
}

\author{
Joshua D. Niforatos ${ }^{1}$
}

Received: 23 June 2017 / Accepted: 10 August 2017 / Published online: 31 August 2017

(C) Academic Psychiatry 2017

\section{Artist's Statement}

This poem was written during a palliative medicine clinical rotation when the author and his classmates were asked to reflect and write on the idea of stillness for five minutes. Upon completion of this short writing exercise, the author experienced a brief, though restorative moment of peace. An anxious spirit constantly "on-the-go", as if controlled by Newton's first law of motion, is a spirit that will find great difficulty in practicing therapeutic stillness with patients who require moments of accompaniment. The personal practice of writing and reflection can help physicians and trainees experience moments of respite and rejuvenation from the daily demands of clinical practice. This poem is an invitation to readers to write or reflect, i.e., to experience the restoration that accompanies brief moments of therapeutic stillness.

Joshua D. Niforatos

jxn187@ case.edu

1 Cleveland Clinic Lerner College of Medicine, Cleveland, OH, USA
Stillness (in 5 minutes)

Agitation. Forced.

Can be good if time

is allocated, for it.

Cannot stop mind from racing.

Getting anxious:

Things to do, places to be,

People to see.

Charts to finish, patients to visit.

Calm, quiet, relax... 1.2.3. 4. 5 .

Nope, not working.

What was that mindfulness technique?

My mantra - mantraaaaa, mamba, manta, amanta,

Amantadine. Shit, I should place that order.

CBT - let's reframe the situation.

Shit. I can't remember how to do that either.

5 minutes of stillness.

I need to round in 20 minutes.

What are others doing? Are they writing, reading, studying?

STOP!!!

Sunny blue skies,

A gentle breeze,

Brilliant greens.

Then again, should I be writing something, more quotidian on the topic?

Point: stillness is about accompaniment, presence in suffering, moments of silence, allowing for the emergence of emotions. Counterpoint: how can I be still with and for others, my patients, you, if I can't be still myself, for...

5 minutes. Done. Back to work. 